\title{
ЭСХАТОЛОГИЯ ВОЛИ В УЧЕНИИ ПРЕПОДОБНОГО МАКСИМА ИСПОВЕДНИКА
}

\author{
Eschatology of Will in the Teachings of Maximus the Confessor
}

\author{
Anatolii Makohon
}

DOI: 10.17846/CL.2018.11.2.3-13

\begin{abstract}
MAKOHON, Anatolii. Eschatology of Will in the Teachings of Maximus the Confessor. The article investigates the will of intelligent beings in the state of deification. Amid various standpoints on presence or absence of gnomic will $(\gamma \nu \omega \dot{\mu \eta})$ in eschaton, the author has conducted the analysis of the act of will in the teaching of Maximus the Confessor. The problem of will has been studied in the context of eschatological views of the father,

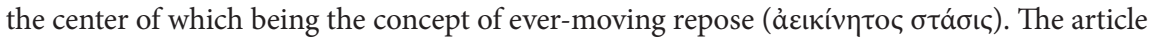
involves the analysis of texts from Great Ethics by Aristotle and Ennead 6.8 by Plotinus, which have not been sufficiently studied by researchers in the analysis of philosophical influences of the Father of the Church. As a result of the analysis, the author brings forward an assumption about a complete absence of the gnomic will and the process of choice as such

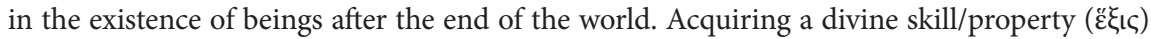
results in deactivation of the gnomic will process at the fifth stage of the act of will - search

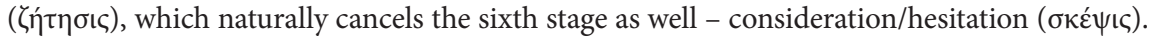
The author finishes the investigation with a critique of personalistic theories that always leave the choice process in the eschaton and subdue the nature to hypostasis assigning the former to the abstract category of a universal and service concept, and considering the latter the stimulus of being for the former leaving behind the apophatic revelation of elusive essence.
\end{abstract}

Keywords: Maximus the Confessor, eschatology, gnomic will, ever-moving repose, free will, free choice, deification

Abstrakt: MAKOHON, Anatolii. Eschatológia vôle v učení Maxima Vyznávača. V článku sa skúma vôla rozumových bytostí v stave zbožštenia. Na pozadí rôznych názorov o prítomnosti alebo absencii gnómickej vôle $\mathrm{v}$ eschatóne autor vypracoval analýzu vôlového aktu v učení Maxima Vyznávača. Problém vôle bol skúmaný v kontexte eschatologických názorov tohto Otca, ktorých centrom je koncept večne pohybovaného pokoja. Článok zahŕňa analýzu textov z Vel'kej etiky Aristotela a Ennead 6.8 od Plotína, ktoré neboli dostatočne spracované pri analýze filozofických vplyvov na myslenie uvedeného Otca Cirkvi. Ako výsledok tejto analýzy autor predpokladá kompletnú absenciu gnómickej vôle a procesu volby ako takého v existencii bytostí po skončení sveta. Výsledkom nadobúdania Božej kvality/návyku je deaktivácia gnómického vôlového aktu na piatom štádiu vôlového aktu - vyhladávania, a toto, samozrejme, ruší aj šieste štádium - preskúmanie/váhanie. Autor zakončuje svoje úvahy kritikou personalistických teórií, ktoré vždy ponechávajú proces volby v eschatóne a podriadujú prirodzenost' hypostáze, ked’ v prvej vidia abstraktnú kategóriu všeobecného, abstraktný koncept služby, a druhú považujú za podnecovatela bytia prvej, pričom opúštajú apofatické odhalenie unikajúcej podstaty.

Klúčové slová: Maxim Vyznávač, eschatológia, gnómická vôla, večne pohybovaný pokoj, sloboda vôle, sloboda výberu, zbožštenie 
Статья представляет собой часть фундаментальной работы по изучению эсхатологии Максима Исповедника $(580$ - 662) в контексте трансформации эллинских философских парадигм. В данном тексте мы исследуем эсхатологию воли, то ее состояние, которое должны приобрести разумные сущности после конца мира с точки зрения учения преподобного Максима. Все цитаты из текстов Максима приводятся в нашем переводе, кроме некоторых, автор перевода которых специально указывается.

\section{1. Введение в проблематику}

Эсхатологическим взглядам Максима ученые уделяли мало внимания, не посвятив этому вопросу ни одной фундаментальной монографии. Первое серьезное рассмотрение эсхатологии византийского богослова сделал Г. У. фон Бальтазар, где он во-первых, рассмотрел протологические основания эсхатологии Максима в его критике оригенизма (von Balthasar 1988, 123-126), а во-вторых, проанализировал концепт апокатастасиса

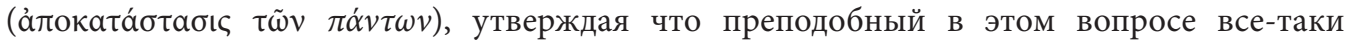
придерживался смягченного оригенизма, а пассажи, говорящие о вечных муках есть лишь пастырские наставления для большинства, которые вуалируют истинные намерения отца, скрытые в «благородном молчании» (von Balthasar 1988, 355-359). Взгляды Г. У. фон Бальтазара были раскритикованы П. Шервудом и Б. Дейли. Первый настаивает на том, что Максим придерживался учения о вечных муках, проводя дефиницию между концептуальным познанием Бога и причастием в реальном мистическом опыте (Sherwood 1955, 205-222), а второй утверждал, что претерпевание спасения возможно только в зависимости от свободного выбора существ, отвечающих на Божественную любовь, а выражения о вечных муках отнюдь не являются только пастырскими наставлениями, но релевантными богословскими текстами (Daley 1982, 334). Взгляды Б. Дейли были критически переработаны Ж.-К. Ларше, который, используя ранее неизвестные тексты в отношении видов карающего огня, утверждал, с одной стороны, его временность, а с другой - вечность. Восстановление природных сил и способностей души в финальном эсхатоне все равно будет сопровождаться вечными мучениями для грешников, и эти муки причиняет сам Божественный огонь, который для праведников, напротив, есть благо (Larchet 1996, 652-662). Претерпевание того или иного состояния зависит от расположения

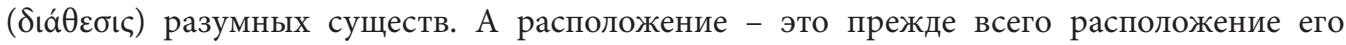
разумной воли, конечное состояние которого и будет определять судьбу человека.

Последнее содержательное исследование эсхатологии Максима Исповедника провел А. Андреопулос, в целом адекватно описав отличие эсхатологии Максима от оригенистского циклизма. Оригенисты использовали модель - «покой (бта́бıৎ) - движение (кívๆбı) становление ( $\gamma \varepsilon ́ v \varepsilon \sigma \iota)$ » - в качестве основания творения мира, в котором движение вызвано пресыщением (ко́роৎ), или желанием познать реальность противоположную благу (т. е. зло), что причиняет движение возвращения в первоначальное единство (غ่vá $\delta \alpha$ ) (Andreopoulos $2015,326)$. В то время как Максим, меняя первый и третий член триады местами, выдвигает

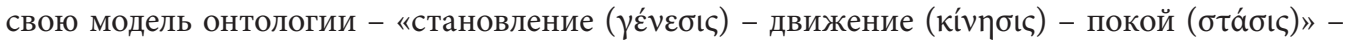

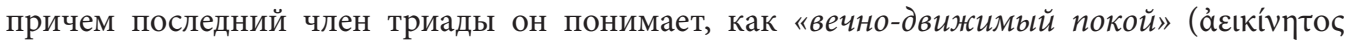

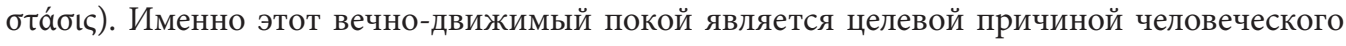
бытия: «Человек не мог, как было уже сказано, разыскать свое начало, которое осталось позади, для того, чтобы познать с помощью него оставленное позади начало, так как до этого он не познал конец из начала» (Maximus Pros Thalassium 59; Maximus 1865e, 613D). Поэтому конец у Максима метафизически первичней начала. Цитируя Аристотеля, он утверждает: 
«Конец есть то, ради чего есть все, сам же он ничего ради» (Maximus Peri diaforon aporion 7; Maximus 1865d, 1072C). Ради этого конца, как цели, Бог и привел в бытие сущность сущих (Maximus Pros Thalassium 60; Maximus 1865e, 621A).

Но сразу возникает проблема: все ли получат спасение в соответствии с такой логикой? Грех определяется не природой, а расположением свободной воли, ведь падение

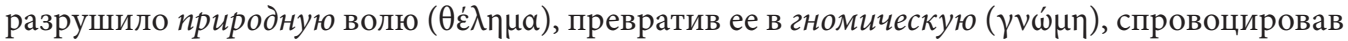
произволение-предпочтение (лрохірєбı)), после чего вместо интеллектуальноинтуитивного постижения Бога, разумное существо вынуждено размышлять, колебаться, сомневаться, прежде чем принять решение. Отвергая автоматизм спасения, и, настаивая на примате свободы, на независимости воли, А. Андреопулоснедостаточно прояснил вопрос ее эсхатологии, который достиг остроты в полемике, возникшей между православными персоналистами и их противниками. Полемика переросла и в эсхатологическую плоскость, в частности, в вопросе о состоянии человеческой воли после эсхатона. Так Г. Беневич настаивает на отсутствии гномической воли в состоянии обожения, в то время как И. Мануссакис, напротив, утверждает ее наличие. Утверждая превосходство личности над природой, последний понимает природу и сущность слишком натуралистично, связывая ее с физиологическими потребностями (Manoussakis 2013, 176). Настаивая на сохранении гномической воли у обоженных людей, он утверждает, что не может быть полного отождествления воли Бога и святых и тождества воль святых друг с другом, но есть их конвергенция, бесконечное приближение друг к другу (Manoussakis 2013, 177-180).

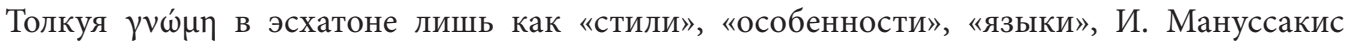

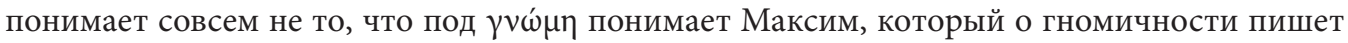
так (в переводе Д. Черноглазова): «один больше подражает тому что по природе, а другой этому не подражает» (Maximus Echeiridia theologika 10; Maximus 1965a, 137B). В связи с этим Г. Беневич, кажется прав, утверждая различие между людьми в эсхатоне согласно мере и характеру любви спасенных, которые у каждого свои. Это их особый тропос существования (Benevich 2014, 180). Сам Максим утверждает, что в отношении логоса природы, воля у всех одна, а в отношении к тропосу движения - разная (Maximus Echeiridia theologika 1; Maximus 1965a, 24C-25A). В результате критики персоналистских теорий имеем следующий взгляд: «Человек не выбирает свой образ существования в Боге (как об этом говорит Зизиулас), а уступает свое самовластие Богу из любви к Нему, в свою очередь обретая в меру этой любви тот уникальный образ-тропос, каким Божия воля исполняется именно в нем» (Benevich 2014, 181).

\section{2. Анализ волевого акта}

Согласившись с основными выводами Г. Беневича относительно деактивации гномической воли, этот вопрос требует более детального философского прояснения в контексте эсхатологии. Дляэтого мы проведем анализ волевого акта, какего видит Максим Исповедник, и сопоставим состояние воли существ, оказавшихся в эсхатоне, с общим эсхатологическим учением преподобного, учитывая основные тексты, его эксплицирующие.

Процесс образования волевого акта у Максима представлен в «Диспуте с Пирром» (перевод Д. Афиногенова): «Ведь то, что по природе разумно, обладает разумным стремлением как природной способностью, которая и называется хотением мыслящей души, посредством которого мы желая помышляем, и, помышляя и желая, хотим. И желая, мы ищем, рассматриваем и советуемся, и судим, и настраиваемся, и предпочитаем, и видим, и пользуемся» (Maximus I genomene; Maximus 1865c, 294C). Но подробнее это 
описано в более раннем тексте преподобного, Opuscula 1 (в переводе А. Шуфрина): «Ведь разумное по природе, обладая в качестве природной способности осмысленным стремлением (которое называется волением мыслящей души), стремится, помышляет и, помыслив хочет. Ведь утверждается про хотение, что это не просто природное, но какоето определенное, то есть отнесенное к какому-то предмету воление; и оно хотяще ищет, и ищуще предусматривает, и предусматривающе прикидывает, и прикидывающе решает, и решающе выбирает, и выбирающе побуждается, и побуждаясь пользуется, и пользуясь упокаивается от устремленного к тому предмету движения» (Maximus Echeiridia theologika 1; Maximus 1865a, 21D-24A).

Исходя из сказанного, выделим схему строения волевого акта: 1) разумная природа

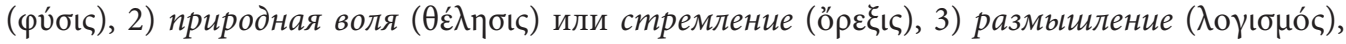

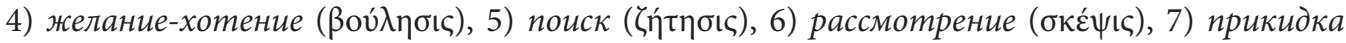

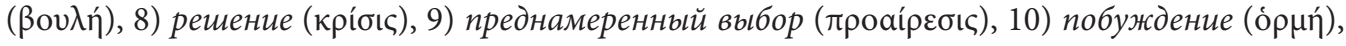

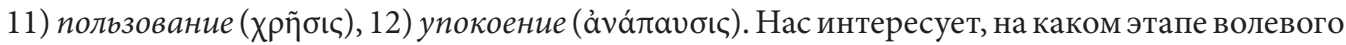
акта начинается деятельность воли, связанная с производством греха, то чего у Христа не могло быть и то, что должно прекратиться у разумных существ в результате эсхатона и воскресения. Определяя природную волю, Максим в том же сочинении утверждает:

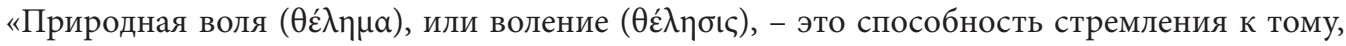
что соответствует природе, и поддержания всех особенностей, сущностно природе присущих. Ибо сущность, природно охваченная волей, стремится быть, жить и двигаться соответственно чувству и уму, влекомая к полноте бытия, соответствующей ее природе» (Maximus Echeiridia theologika 1; Maximus 1865a, 12C-12D). Напротив, предпочтение

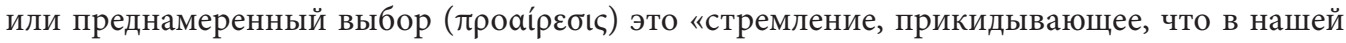
власти» (Maximus Echeiridia theologika 1; Maximus 1865a, 13A). Максим утверждает, что

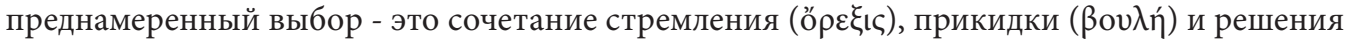
(крі́бı), то есть преднамеренный выбор обуславливается прибавлением к естественному стремлению (о̋ $\rho \xi ı)$, которое соответствует 2-му звену цепи волевого акта, 7-го и 8-го

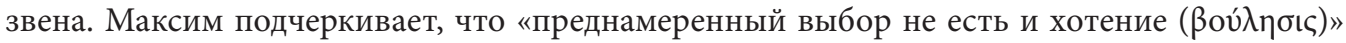
(Maximus Echeiridia theologika 1; Maximus 1865, 13В), то есть 4-е звено. Но что бы понять, как проникает зло в человеческую волю, Максимом вводится новое понятие, которого не было у его предшественников, разрабатывавших теорию волевого акта (Аристотель, Григорий Нисский и Немезий Эмесский). Это довольно сложное понятие гномчческой воли $(\gamma \nu \omega ́ \mu \eta)$, или намерения, которое в этом же произведении определяется Максимом как «стремлением к тому, что в нашей власти, из которого исходит преднамеренный выбор; или

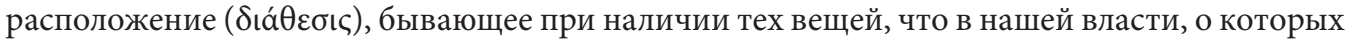
сделана (с возбуждением стремления) прикидка» (Maximus Echeiridia theologika 1; Maximus 1865a, 17С). Здесь же гномическая воля называется расположенным стремлением. Как понимать это расположение ( $\delta$ เá $\theta \varepsilon \sigma \iota \varsigma)$, или, иначе говоря, настрой? Термин расположениенастроение ( $\delta \iota \tau \imath \theta \dot{\varepsilon} \mu \varepsilon \theta \alpha)$ используется в Диспуте с Пирром, в вышеуказанной цепочке образования волевого акта (Maximus I genomeni; Maximus 1865c, 294C). Здесь же приводится иное определение гномической воли (в переводе Д. Афиногенова используется термин намерение): «намерение есть не что иное, как какое-нибудь хотение, относительно придерживающееся или настоящего, или мнимого блага» (Maximus I genomeni; Maximus 1865 c, 308C). Добавляя к этому утверждение из Opuscula 1, что гномическая воля или намерение становится таковым в результате стремления, расположенного к тому, о чем было решено на основании прикидки (Maximus Echeiridia theologika 1; Maximus 1865a, 17C), Максим выводит преднамеренный выбор из гномической воли (намерения), говоря, что гномическая воля относится к преднамеренному выбору как навык (ह̌६ı)) к деятельности 


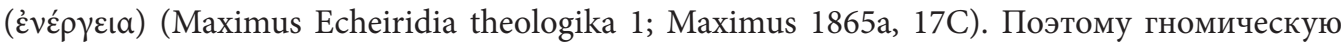
волю можно по-другому назвать расположением, вошедшим в привычку, или в навык, что и делают некоторые исследователи (Larchet 1996, 138). И еще отметим, что гномичность предполагает не только реальное, но и мнимое благо, что в ситуации эсхатона уже не будет иметь место, ибо мнимого блага больше не будет.

\section{3. Состояние воли после Воскресения}

В одном из ранних произведений преподобный отвечает на вопроспо поводу сомнительного учения св. Григория Нисского об апокатастасисе: «А третье - то, которое часто употреблял

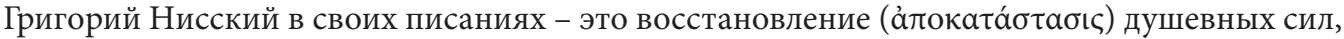
подвластных греху, обратно ( $\pi \dot{\lambda} \lambda ı v)$ к тому состоянию, в котором они были сотворены. Ибо необходимо, чтобы как вся природа в воскресении плоти получила бессмертие в ожидаемое время, так и извращенные силы души по прошествии веков отложили бы воспоминания о пороке, внедренные в нее; и проходя все века и не находя покоя, достигли бы беспредельного Бога. Таким образом, посредством знания, а не причастностью благам,

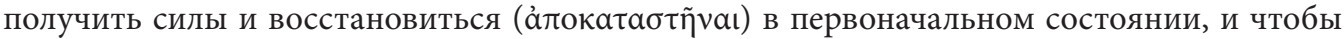
Творец показался как не являющийся причиной греха» (Maximus Pefseis kai Apokriseis 19, 10-22; Maximus 1982, 17-18). Таким образом, душа после свершения веков больше не будет видеть мнимого блага, которое она могла бы ошибочно выбирать благодаря своей гномической воле. Душа получает в обожении, подобие Христа, который, как неоднократно подчеркивалось преподобным, не имеет гномической воли (Maximus Echeiridia theologika 1; Maximus 1865a, 192D-193A; Maximus I genomeni; Maximus 1865c, 308B-313A).

В ином месте Максим говорит о любви в контексте неразлучного бытия с Богом, что и являет собой эсхатологическое состояние, ибо любовь настраивает гномическую волю, что бы та следовала природе, и не восставала против нее, тогда-то мы и обретаем с Богом и другими людьми одну волю и одно желание (Maximus Epistoli 2; Maximus 1865b, 396C). Это перекликается с другим высказыванием Максима о едином действии Бога и святых (Maximus Peri diaforon aporion 7; Maximus 1865d, 1076C), породившем целую волну как критических замечаний (Sherwood 1955, 155; Riou 1973, 68; Garrigues 1974, 284) с обвинениями раннего Максима в моноэнергизме, так и наоборот, защитительных толкований (Thunberg 1995, 228-229; Larshet1996, 559-562). Сам Максим уточнял эту раннюю формулировку о «едином действии Бога и святых», говоря в поздних текстах о том, что «в отношении логоса природы воление у всех окажется одним, а в отношении тропоса - разным» (Maximus Echeiridia theologika 1; Maximus 1865a, 25A), развеивая все недоразумения.

Толкуя слова Григория Богослова, Максим пишет о состоянии обоженных после свершения веков: «Ибо тогда не будет чего-либо являемого вне Бога, или кажущегося равным Богу, чтобы оно соблазнило уклонить к нему чье-либо влечение, поскольку все - и умопостигаемое, и чувственное - будет объято им в неизреченном Его явлении и пришествии» (Maximus Peri diaforon aporion 7; Maximus 1865d, 1076D-1077A). Мы видим здесь отсутствие выбора мнимого блага, который характеризовал гномическую волю. Так как нет уже двусмысленности преднамеренного выбора из-за актуального состояния обожения, то действовать будет только природное стремление ума. Обоженный будет находиться в состоянии наслаждения: «Пресыщение (ко́роৎ) этим наслаждением есть нарастание до бесконечности самого стремления наслаждающихся (так что каждый настолько сверх природной меры причастится, насколько изошел желанием)» (Maximus Echeiridia theologika 1; Maximus 1865a, 24C-24D). Это высказывание Максима коррелирует 


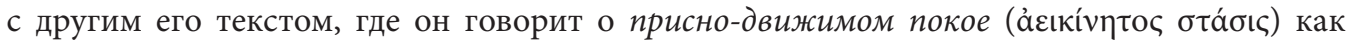

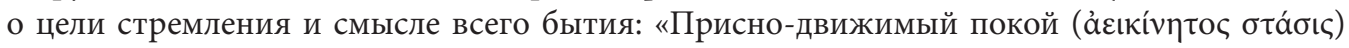
вокруг предмета желания [...] есть постоянное и непрерывное наслаждение желанным» (Maximus Pros Thalassium 59; Maximus 1865e, 608D). Именно в единении с Богом, обоженное существо приобретает свойство-навык (ह̌) ц) Бога. А этот термин как раз характеризовал гномическую волю, но тогда он относился к человеческому свойству-навыку расположения, который мог предопределять преднамеренный выбор (лроаірєбเৎ). Теперь же свойствонавык - божественное, и оно становится достоянием обоженного человека, который уже не выбирает Бога в бесконечности Его постижения. Есть несколько высказываний Максима

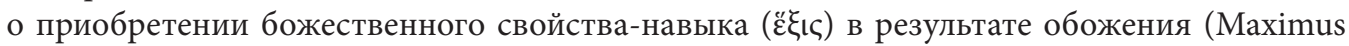
Epistoli 1; Maximus 1865b, 376B; Maximus Peri diaforon aporion 20; Maximus 1865d, 1241C; Maximus Pros Thalassium 6; Maximus 1865e, 281A). Заметим, что первый из этих фрагментов написан в контексте гибели всего мира, где подчеркивается, что «ничто из существующего не останется в теперешнем виде» (Maximus Epistoli 1; Maximus 1865b, 376B). Поэтому, новое

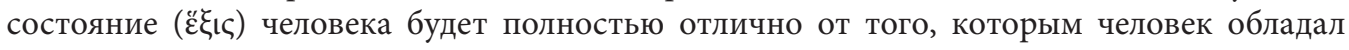
в преходящем мире, и которое характеризовало его гномическое расположение.

\section{4. Философские импликации}

О влиянии на Максима сочинения Немесия Эмесского «О природе человека» и Аристотелевого текста «Никомахова этика» было сказано немало (Petrov 2017), но практически никто, кажется, не сделал серьезного анализа сходства Максимового учения

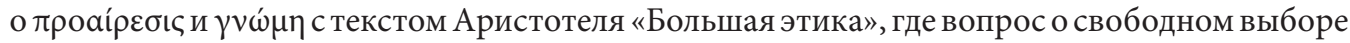

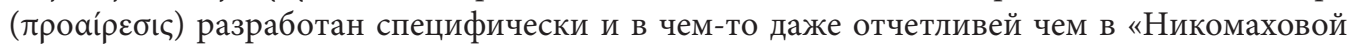
этике».

В «Большой этике» о свободном выборе (лроаі́рєбı)) сказано, что он сопровождается рассуждением (†́ үà

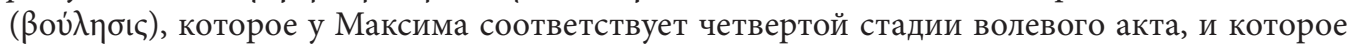
Максим так же отличает от преднамеренного выбора (Aristoteles Ethikon megalon 1.17; Aristoteles 1935, 1189a 1-13; Maximus Echeiridia theologika 1; Maximus 1865a, 13В). Выбор направлен не на саму цель, а на то, что ведет к цели, и он касается предпочтения лучшего или худшего (Aristoteles Ethikon megalon 1.17; Aristoteles 1935, 1189a 15). Но выбора по

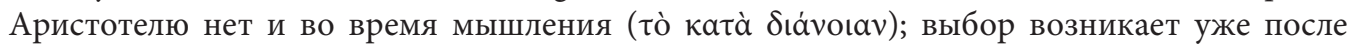

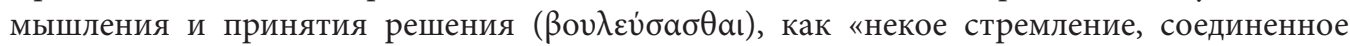

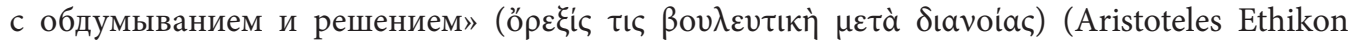
megalon 1.17; Aristoteles 1935, 1189a 20-21, 26-33). Очень похожие выражения можно найти и у Максима (Maximus Echeiridia theologika 1; Maximus 1865a, 13A, 13B, 13C, 16C).

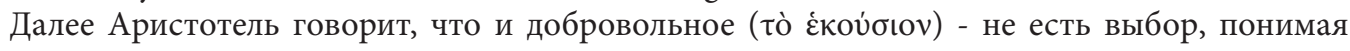
добровольное как то, что мы совершаем без предварительного обдумывания, тогда как выбор всегда связан уже с обдуманным и уже принятым решением (Aristoteles Ethikon megalon 1.17; Aristoteles 1935, 1189a 32-35). Это высказывание так же коррелирует с высказываниями Максима о свободе воли ( $\dot{\xi}$ оvбі́a), которую он определяет, как то, что в нашей власти, или как самовластие (Maximus Echeiridia theologika 1; Maximus 1865a, 17D). Но самое интересное сопоставление можно провести с высказываниями Аристотеля по

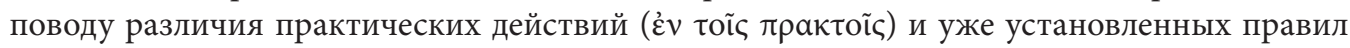

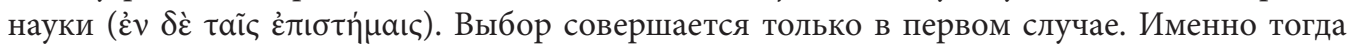
возможна ошибка (立арті́) (слово которое в христианстве стало обозначать грех), тогда 
как в обдумывании в рамках установленного правила ее нет (Aristoteles Ethikon megalon 1.17; Aristoteles 1935, 1189b 18-23). «Где не может быть ошибки при обдумывании, там не

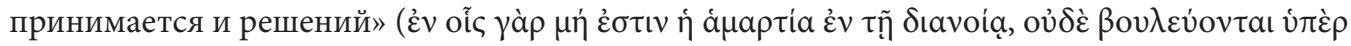
$\tau o v ́ \tau \omega v$ ) (Aristoteles Ethikon megalon 1.17; Aristoteles 1935, 1189b 23-25). Но именно такая ситуация познания будет существовать в состоянии обожения, когда человек не действует, апретерпевает воздействие обожения со стороны Бога, приобретая Божественное свойствонавык. А ведь гномическая воля определялась Максимом как «стремление, расположенное к тому, о чем решено на основании прикидки» (Maximus Echeiridia theologika 1; Maximus 1865a, 17C). Но если нет прикидки и решения даже в теоретической науке по Аристотелю, то о какой гномической воле может идти речь в состоянии обожения?

Так же трохі́рєбı отсутствует у богов в неоплатонизме. Как было показано некоторыми

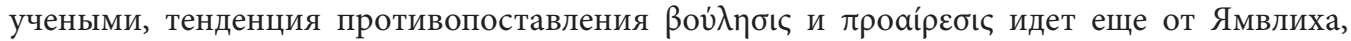
который говорит, что божественное желание блага превосходит жизнь по преднамеренному выбору, а Прокл уже конкретно утверждает, что у богов совершенно нет выбора (проаі́рєбьৎ),

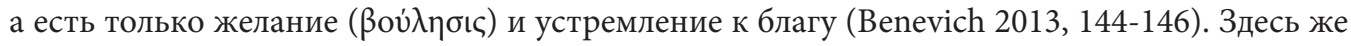

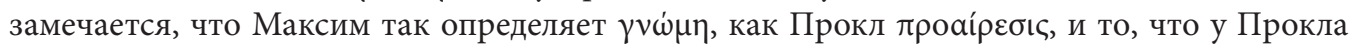

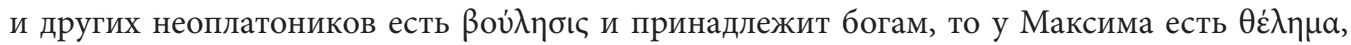
которая остается у святых в состоянии обожения (Benevich 2013, 145,147).

Источник такого воззрения содержится у Плотина, который свободу воли приписывает простому и непостижимому Единому, которое не испытывает нужды в выборе. Учение Плотина о воле никто серьезно не сравнивал с учением о воле Максима, если не считать кратких упоминаний на Еннеаду 6.8., и нескольких замечаний Дж. Фаррела $(1989,46,50)$. Но упомянутый автор в своем исследовании впадает в неточность, допуская наличие свободного выбора у святых в эсхатоне, как множества объектов, в соответствии с множеством предсуществующих в Боге логосов, заявляя также, что для Максима нет разницы между свободой и свободным выбором (Farrell 1989, 114, 130, 154). Тогда как, на наш взгляд, это принципиально не так, и выше мы показали, что выбор - не есть свобода воли, ведь объект желания и воли в состоянии обожения - один, это - Единый Бог. Но вот тропосы этого воления, совершенно различны у каждого, как способы любви. И эти тропосы как раз и соответствуют множественности логосов в едином Логосе. Это дает возможность Максиму утверждать, что: «многими логосами является Один Логос, и Одним - многие; и Один - многими - в соответствии с творческим и непрерывным, благоприличным

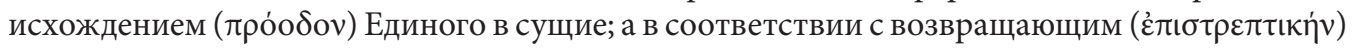
и руководящим перенесением и промыслом многих к Единому, словно во вседержительное начало или центр, заранее содержащий начала лучей [исходящих] из него и как собирающий все, многие [являются] Одним» (Maximus Peri diaforon aporion 7; Maximus 1865d, 1081B-C). То есть никакого множества объектов желания, помимо Единого Бога при возвращении к Нему в эсхатоне не будет. Соответственно не будет и выборности.

Философия Плотина оказала значительное влияние на взгляды Максима, если и не непосредственно, то благодаря отцам-каппадокийцам. Плотин говорит, что «мы называем

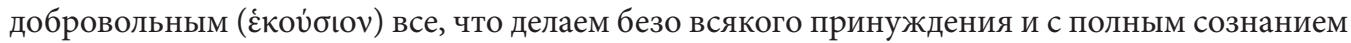
совершаемого» (Plotinus Enneada 6.8.1. 33-34; Plotinus 1988, 228), следуя в этом Аристотелю. Но как платоник он говорит, что настоящее добровольное воление должно содержать истинное знание (Plotinus Enneada 6.8.1. 39-41; Plotinus 1988, 230). Далее он говорит, что

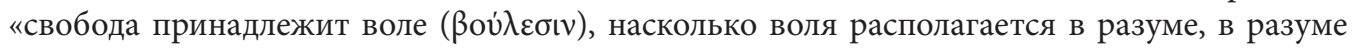
правильном, то есть обладающем правильным знанием» (Plotinus Enneada 6.8.3. 2-5; Plotinus 1988, 234). А правильное знание - это то, которое не зависит от воображения и не подчинено никаким страстям, которые рождаются в ослабленном теле, поэтому 
по-настоящему свободны только те существа, которые руководятся только Умом, то есть боги, живущие в согласии с Умом и своими желаниями соответствующие энергиям Ума (Plotinus 6.8.3. 8-26; Plotinus 1988, 234, 236). Эта мысль, послужив источником дальнейших спекуляций неоплатонизма, явилась основанием и для Максима Исповедника. Для Плотина совершение ошибки, что и есть свобода выбора (но не свобода воли), связана с падением души и непроизвольным актом, то есть несвободой (åкоv́бıоv). С точки зрения Плотина: «Мы действительно выбираем подобное, введенные в заблуждение нашим окружением или нашими страстями, полагая, что эти вещи принесут нам различные блага» (Rist 2005, 157). Выбор совершается только в падшем мире, а в сфере Ума, наоборот, царит свобода и совершенное знание. Эту мысль можно сопоставить и с утверждением Максима о том, что Бог не обладает ведением сложным и составленным из противоположностей (Maximus Pros Thalassium 44; Maximus 1865e, 416C). Такое же ведение будет свойственно обоженным существам, которые не будут больше не только прикидывать (ßоv入и́) или судить-решать

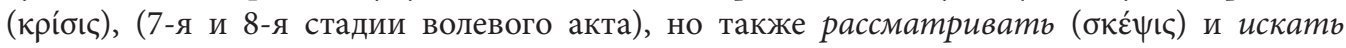

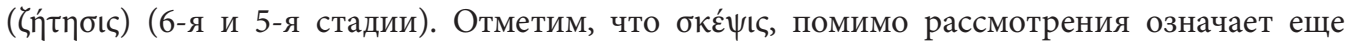
колебание и сомнение, то есть те состояния, которых не должно быть у обоженных существ,

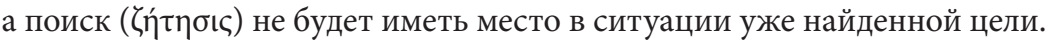

\section{5. Выводы об эсхатологическом состоянии воли}

Итак, в состоянии финального свершения мира и человека, с точки зрения эсхатологии воли Максима Исповедника, в соответствии с мысленным взором чистых (Maximus Mystagogia I 158-159; Maximus 2011, 12), когда Бог будет всем во всем (1 Кор 15:28), остаются только первые четыре стадии волевого акта. Первая ступень - это собственно сама

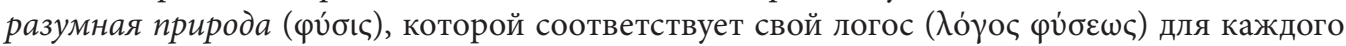

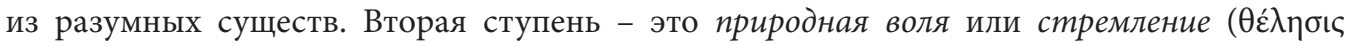

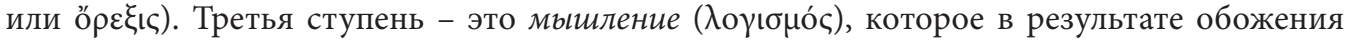
преображается скорее в vónбı,, интуитивное умозрение. И четвертая ступень - это

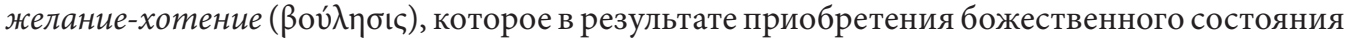

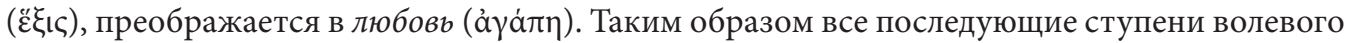
акта будут деактивированы, а различия между существами будут определяться свободой

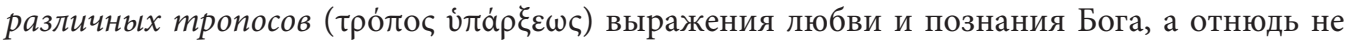
свободой выбора в гномическом преднамеренном процессе.

Делая заключение, мы можем, как нам кажется, отвергнуть точку зрения персоналистов, сохраняющих выборность в вопросе эсхатологии воли. Это связано с тем, что они утверждают превосходство ипостаси над природой, говоря, что «природа находится во владении ипостаси» (Zizioulas 2013, 89), и что «личность побуждает природу существовать» (Zizioulas 2013, 90), что звучит неприемлемо в русле всего святоотеческого учения. Не останавливаясь на подробной критике персоналистов, добавим, что в их поле зрения попадает природа Бога, трактуемая ими как нечто общее и абстрактное, призванное лишь сплачивать ипостаси, а Бог понимается не только как единое, но и как единичность, хотя Он есть скорее троичность. Здесь, как нам видится, нет того апофатического понимания природы, которое только и может отрицательным образом раскрыть, свою ускользающую сущность, которую персоналистский взгляд пытается заключить в некую абстрактную всеобщность, как довесок к ипостасной свободе. Персоналистский взгляд, конечно, будет вынужден оставить выборность и гномичность воли, ибо иначе воля была бы лишь абстрактной и общей категорией своей природы, всего лишь придатком к свободе 
выбора. Однако, как показал наш анализ свободной воли в состоянии обожения, дополняя последние исследования Г. Беневича привлечением текстов Аристотеля («Большая этика») и Плотина, никакой гномичности или выборности не может быть у разумного существа

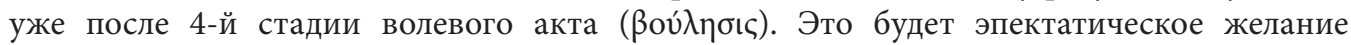
недостижимого Божества, в вечно-движимом покое любовного томления, которое никогда не сможет ни насытиться, ни пресытиться желанным, в бесконечном приближении к неутолимой, но от этого еще более желанной сладости Божественной благодати.

\section{REFERENCES}

Andreopoulos, Andreas. 2015. Eschatology in Maximus the Confessor. In Allen, Pauline - Neil, Bronwen (eds.). The Oxford Handbook of Maximus the Confessor. Oxford, 322-340.

Aristoteles. 1935. Ethikon megalon [Magna moralia]. In Armstrong, G. Cyril (ed.). Aristotle vol. 18. Cambridge Mass.

von Balthasar, Hans Urs. 1988. Kosmishe Liturgie: Das Weltbild Maximus' des Bekenners. Einsiedeln.

Benevitch, Georgii. 2013. Об отсутствии ПРОАІPE $\Sigma$ I $\Sigma$ у богов в неоплатонизме и параллель в христианской мысли [On the Absence Proairesis from the Gods in Neoplatonism and Parallel in Christian Thought]. In Вестник русской христианской гуманитарной академии [The Bulletin of Russian Christian Humanitarian Academy] 14/3, 143-148.

Benevich, Georgii. 2014. Богословско-полемические сочинения прп. Максима Исповедника и его полемика против моноэнергизма и монофелитства [Theological-polemical writings of St. Maximus the Confessor and his polemics against monoenergism and monothelitism]. In Benevich, Georgii (ed.). Прп Максим Исповедник. Богословско-полемические сочинения [St. Maximus the Confessor. Theological-polemical writings]. St. Petersburg, 11-298.

Daley, Brian. 1982. Apokatastasis and "Honorable Silence" in Eschatology of Maximus the Confessor. In Heinzer, Felix - Schonborn, Christoph (eds.). Maximus Confessor: Actes du Symposium sur Maxime le Confesseur, Fribourg, 2 - 5 septembre 1980. Fribourg, 309-339. Farell, Joseph. 1989. Free Choice in St Maximus the Confessor. South Canaan.

Garrigues, Juan Miguel. 1976. Maxime le Confesseur: charite, avenir divin de l'homme. Paris. Larchet, Jean-Claude. 1996. La divination de l'homme selon saint Maxim le Confesseur. Paris.

Maximus. 1865a. Maximus Echeiridia theologika kai polemika [Opuscula Theologica et Polemica]. In Migne, Jaques Paul (ed.). Patrologia Graeca 91. Paris.

Maximus. 1865b. Maximus Epistolia [Epistola]. In Migne, Jaques Paul (ed.). Patrologia Graeca 91. Paris.

Maximus. 1865c. Maximus I genomene en Afrikei dialexis tou Maximou pros Pyrron [Disputacio cum Pyrrho]. In Migne, Jaques Paul (ed.). Patrologia Graeca 91. Paris.

Maximus. 1865d. Maximus Peri diaforon aporion ton agion Dionysiou kai Gregoriou [De Variis Difficilibus Locis Sanctorum Dionysii et Gregorii]. In Migne, Jaques Paul (ed.). Patrologia Graeca 91. Paris.

Maximus. 1865e. Maximus Pros Thalassion [Ad Thalassium]. In Migne, Jaques Paul (ed.). Patrologia Graeca 90. Paris.

Maximus. 1982. Maximus Pefseis kai Apokriseis [Quaestiones et Dubia]. In Decklerck, Jose (ed.). Corpus Christianorum, Series Graeca 10. Brepols-Turnhout.

Maximus. 2011. Maximus Mystagogia [Mystagogia]. In Boudignon, Cristian (ed.). Corpus Christianorum, Series Graeca 69. Brepols-Turnhout. 
Manoussakis, John. 2013. The Dialectic of Communion and Otherness in St Maximus' Understanding of the Will. In Vasiljevic, Maxim (ed.). Knowing the Purpose of Creation through the Resurrection. Alhambra, 159-180.

Petrov, Valerii. 2017. Arist. Nicom. Ethic. III 4,1111b4-7, 1113b22 Как источник концептуального аппарата в учении Максима Исповедника о волении и волевом акте [Arist. Nicom. Ethic. III 4, 1111b4-7, 1113b22 As the Source of the Conceptual Apparatus In Maximus the Confessor's Teaching about Will and Volitional Act] In $\Sigma \mathrm{HO} \Lambda \mathrm{H}$ [Schole] 11/2, 393-406.

Plotinus. 1988. Plotinus Enneads VI. 6.-9. In Armstrong, Arthur Hilary (ed.). Plotinus with an English Translation, vol. VII. Cambridge-London.

Riou, Alain. 1973. Le Monde et l'Eglise selon Maxime le Confesseur. Paris.

Rist, John 2005. Плотин: путь к реальности [Plotinus: The Road to Reality]. St. Petersburg.

Sherwood, Polikarp. 1955. The Earlier Ambigua of Saint Maximus the Confessor and His Refutation Of Origenism. Romae.

Thunberg, Lars. 1995. Microcosm and Mediator. The Theological Antropology of Maximus the Confessor. Chicago and La Salle.

Zizioulas, John. 2013. Person and Nature in the Theology of St Maximus the Confessor. In Vasiljevic, Maxim (ed.). Knowing the Purpose of Creation through the Resurrection. Alhambra, 85-114.

SUMMARY: ESCHATOLOGY OF WILL IN THE TEACHINGS OF MAXIMUS THE CONFESSOR. The article discusses the eschatological state of will of intelligent beings in the teaching of the Byzantine theologian and philosopher Maximus the Confessor. The problem of the final state of human existence rests in a different understanding of freedom expressed in the categories of will. Some researchers accept the existence of the gnomic will in eschaton, others talk about its deactivation. We examine the problem through the prism of eschatological teaching of the reverend father where the end of existence metaphysically supersedes the beginning, which was reflected in Maximus's critique of origenism. We further look into the process of the act of will that consists of twelve stages starting from the intelligent nature and its volition and finishing with making a decision and repose. We have identified stages at which the natural will becomes a gnomic one transitioning to the state of deliberate choice, which is connected with sin. Researching Maximus the Confessor's relevant works on deification and eschatological state of beings, we have shown the absence of the process of choice and gnomic will in eschaton. The research analyses the texts of the Great Ethics by Aristotle and Ennead 6.8 by Plotinus which have not been sufficiently studied in the context of the research on Maximus's eschatology. As a result of the analysis we have identified that gnomic process is deactivated at the verge of the stages four (volition) and five (search) which naturally leads to the cancelling at the stage six (consideration/hesitation) as well. This allows us to critically reassess the views of personalists on the free choice and the free will. Personalists valorize hypostasity at the cost of nature, which they understand too abstractly and functionally, neglecting its apophatic truth which also impacts the teaching about will the freedom of which, according to the teaching of Maximus the Confessor, should not be limited by a deliberate choice process. 
Anatolii Makohon, $\mathrm{PhD}$ student Sumy State University

Department of Philosophy 2, Rymskogo-Korsakova st. 40007 Sumy

Ukraine

anatoly.makogon@gmail.com 